\title{
Aluminum Combustion under Different Condition: A Review
}

\author{
Haidzar Nurdiansyah ${ }^{\mathrm{a}}$, M. Miftahul A $^{\mathrm{b}}$, Fabrobi Ridha ${ }^{\mathrm{c}}$ \\ a,b,c Mechanical Engineering Department, Engineering Faculty, University of Jember \\ e-mail: haidzarbagus@gmail.com
}

\begin{abstract}
This paper reviews the collection of literature on aluminum combustion, with an emphasis on various parameters used. These parameters which affect combustion of aluminum are particles size and oxygen content. Aluminum is a material that is often used in combustion processes due to its effortless reactive material and explosive. A large amount of research has been published about combustion in aluminum materials where aluminum can be used as a way to increase propulsion in combustion. The purpose of this paper is to review some aspects that affect combustion in aluminum. It goes on to discuss the particles size differences and the different oxygen content mixture with gas in used. The results of various existing studies show that there is a difference in ignition temperature and burning time effect in aluminum combustion due to the size and oxygen content. Where, decreasing particles size can decrease ignition temperature and burning time. The review paper is intended to outline a parameter range for aluminum combustion.
\end{abstract}

Keywords: Aluminum Combustion; Burning rate; Particles Size Effect Temperature

\section{INTRODUCTION}

Aluminum is a reactive material that can be used as fuel added for propellant, ethanol, $\mathrm{CH} 4$ and solid-fuel [1-4]. Aluminum also has a high energy density and is also low in cost [5]. Various gases are used by researchers to be used as a mixture of combustion processes such as $\mathrm{O}_{2}, \mathrm{CO}_{2}, \mathrm{Ar}, \mathrm{N}_{2}$ [6-8]. Aluminum combustion with $\mathrm{H} 2 \mathrm{O}$ has also been studied and produced an exogenous $\mathrm{H}_{2}$ gas content [9]. So that various studies on aluminum burning still continue to this day. Aluminum induction and combustion occurs starting when entering the melting process to the boiling point and continued with oxidation.

Sundaram et al. [10] the process of induction and combustion on aluminum particles with nanometer size has fewer steps when compared to aluminum with a micrometer size, namely at the nanometer size there are 3 stages while the micrometer size has 4 stages until combustion occurs. Melting behavior of aluminum powder was conducted using aluminum particle produced by milling process. Particle synthesis was carried out with the size of 13 to $40 \mathrm{~nm}$ using mechanical attrition under different atmospheres, and differential calorimetry scanning was carried out to determine the behavior of aluminum melting. Melting behavior studies have also been carried out using molecular-dynamics (MD) with a size of 1.0-2.9 nm [11, 12]. This shows the behavior of particles towards the ignition process in aluminum, where the smaller the particle size, the faster the ignition process in aluminum.

AlO emissions were observed in different particles, 2.8 and $10 \mu \mathrm{m}$ in the aluminum combustion process with a temperature of $2650 \mathrm{~K}$ and a pressure of $8 \mathrm{~atm}$ [6]. From various starting point variations of ignition temperatures $1500,2000,2300$, and $2800 \mathrm{~K}$ there is a decrease in ignition time from $25 \mu \mathrm{s}$ for $\mathrm{T}=1500 \mathrm{~K}$ to $0.5 \mu \mathrm{s}$ for $\mathrm{T}=2800 \mathrm{~K}$ with final equilibrium temperature 3742-3833 K[13]. Combustion of aluminum particles in oxygen 
with a size of $10 \mu \mathrm{m}$, temperature $2650 \mathrm{~K}$ with a pressure of 3-30 atm, showing that the reaction process of the particle surface has a significant influence on the combustion behavior of aluminum particles[14]. The reaction enthalpy for particles from 2-10 nm decreases with increasing particle size and can reduce the surface fraction of atoms by hanging bonds. Also, when the particle size decreases, it gives the effect of increasing the rate of agglomeration [15].

From the background above, this paper aims to provide an overview of several things related to the effect of particle size on ignition temperature, burning time and also the effect of oxygen content on aluminum combustion under various conditions. It focused on the recent progress of aluminum combustion and use narrative approach in reviewing the related papers.

\section{Mechanism of Aluminum Combustion}

When aluminum particles burn as depicted in Figure 1, a small portion of the product remains as vapor and a small portion condenses. Oxide vapor in the flame region can diffuse to the surface or the environment. The oxide vapor diffuses to the surface of the particles to condense, the increase in aluminum vapor increases. Steam that diffuses into the environment may or may not condense. The condensed phase is kept away from the fire zone based on the bulk gas movement. The vapors that diffuse into the environment and the condensed phase do not significantly affect the rate of combustion of particles.

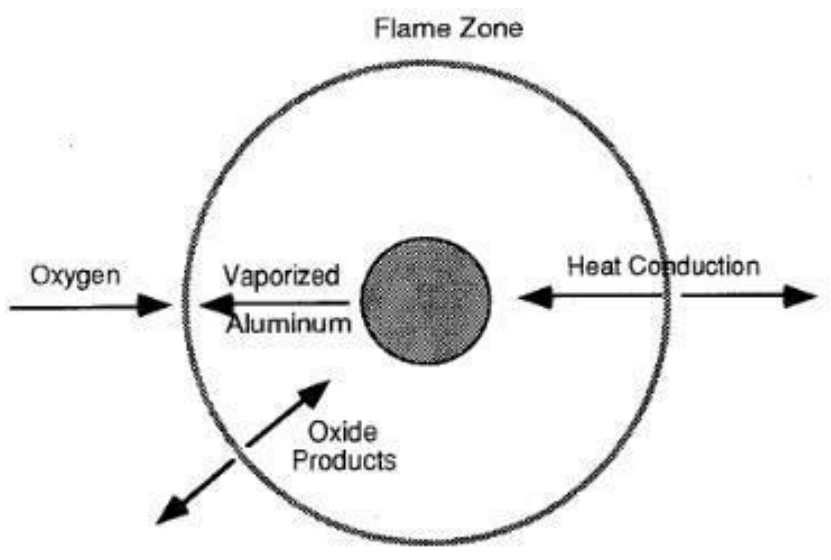

Figure 1. Model diagram of aluminum combustion [16]

At oxidizing concentrations or low gas temperatures, the gas moves towards the fire and the temperature of the fire is below the boiling point of the oxide. When the concentration of the oxidizer or the temperature of the gas increases, the temperature of the flame reaches the boiling point of the oxide and the evaporated oxide fraction begins to increase. The amount of the evaporated oxide is higher which results in an increase in diffusion of matter so that it moves away from the flame and the gas flow between the flame and infinity changes direction. At oxidizing concentrations or high gas temperatures, all oxides are evaporated and the temperature of the flame also rises [16].

When aluminum particles are heated, the weight of the particles is reduced due to moisture evaporation. As the temperature increases, the oxidation reaction of the aluminum surface with oxygen is greatly strengthened. At the peak oxidation temperature, the rate of the oxidation reaction reaches a peak value. However, as the thickness of the oxide layer increases on the surface of aluminum particles, the resistance of oxygen diffusion to the surface of simple aluminum material will greatly increase. To some extent, surface oxidation on aluminum particles will be hindered because of the alumina shell. As the temperature rises higher than the melting point of aluminum material, the core of aluminum particles wrapped in alumina skin will melt. Even at high temperature conditions, melted aluminum will evaporate and cause alumina skin to be damaged. In this case, liquid and aluminum will cause combustion reactions [17] as in Figure 2. 


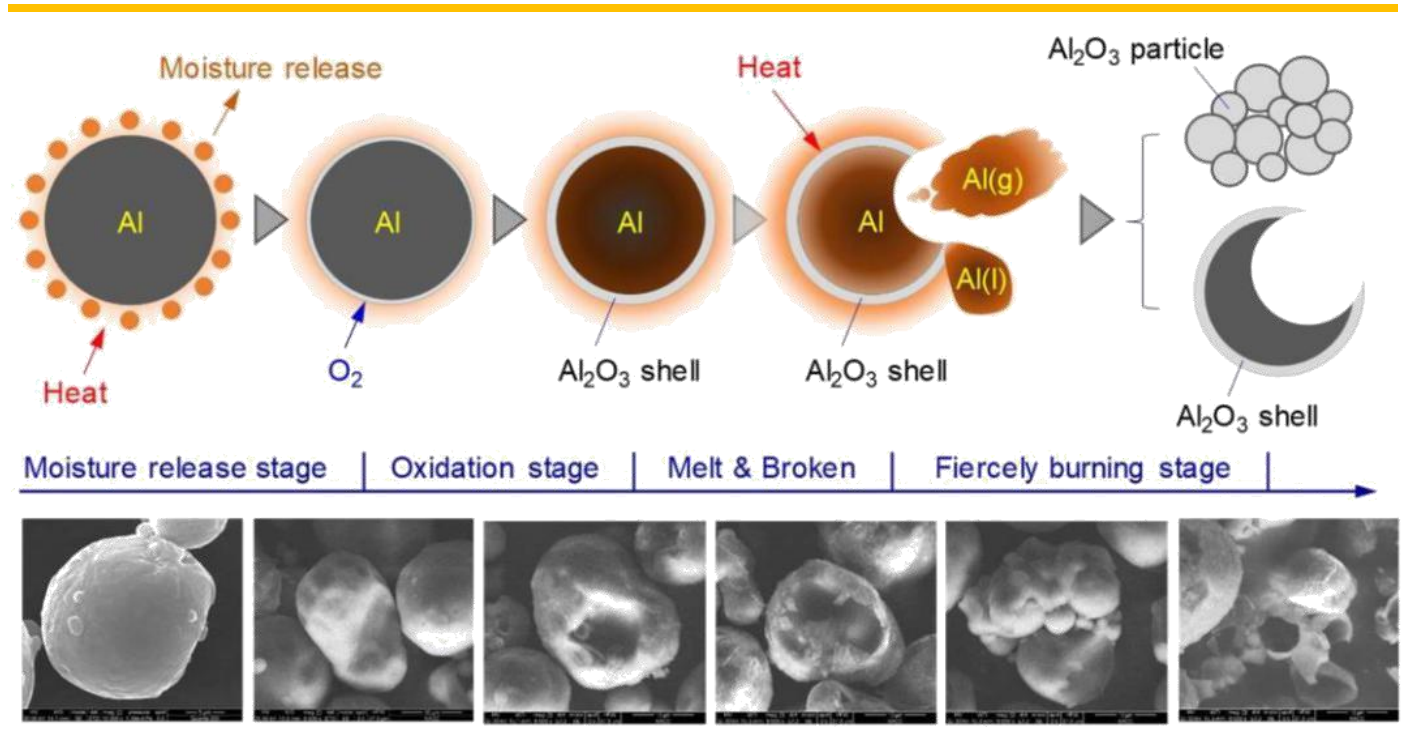

Figure 2. Oxidation diagram on aluminum [17]

This oxidation process is also explained by several researchers through TGA testing [18-20] so that the oxidation behavior can be known. This oxidation process is accompanied by an energy release $[10,13-15,21]$ by being influenced by particle size, gas pressure, and oxygen content. Table 1 is a sub-mechanism of Al's reaction to $\mathrm{O}$ where each reaction has a different energy. Limiting dust to aluminum particles may be achieved in the air. The kinetic mechanism of the $\mathrm{Al} / \mathrm{O}$ gas phase, consisting of 8 species and 10 reactions, as listed in Table 1, is used to simulate chemical processes [13].

Table 1. Al/O sub-mechanisms [13]

\begin{tabular}{ccccc}
\hline No. & Reactions & $\boldsymbol{A}\left(\mathbf{c m}^{3} / \mathbf{m o l ~ s}\right)$ & $\boldsymbol{n}$ & $\boldsymbol{E}(\mathbf{c a l} / \mathbf{m o l})$ \\
\hline 1 & $\mathrm{Al}+\mathrm{O}_{2}=\mathrm{AlO}+\mathrm{O}$ & $9.72 \mathrm{E} 13$ & 0. & 159.95 \\
2 & $\mathrm{Al}+\mathrm{O}+\mathrm{M}=\mathrm{AlO}+\mathrm{M}$ & $3.0 \mathrm{E} 17$ & -1.0 & 0. \\
3 & $\mathrm{AlO}+\mathrm{O}_{2}=\mathrm{OAIO}+\mathrm{O}$ & $4.62 \mathrm{E} 14$ & 0. & 19885.9 \\
4 & $\mathrm{Al}_{2} \mathrm{O}_{3}=\mathrm{AIOAIO}+\mathrm{O}$ & $3.0 \mathrm{E} 15$ & 0. & 97649.99 \\
5 & $\mathrm{Al} 2 \mathrm{O} 3=\mathrm{OAIO}+\mathrm{AIO}$ & $3.0 \mathrm{E} 15$ & 0. & 126999.89 \\
6 & $\mathrm{AlOAIO}=\mathrm{AlO}+\mathrm{AIO}$ & $1.0 \mathrm{E} 15$ & 0. & 117900. \\
7 & $\mathrm{AlOAIO}=\mathrm{Al}+\mathrm{OAIO}$ & $1.0 \mathrm{E} 15$ & 0. & 148900. \\
8 & $\mathrm{AIOAIO}=\mathrm{AlOAI}+\mathrm{O}$ & $1.0 \mathrm{E} 15$ & 0. & 104249.94 \\
9 & $\mathrm{OAIO}=\mathrm{AlO}+\mathrm{O}$ & $1.0 \mathrm{E} 15$ & 0. & 88549.86 \\
10 & $\mathrm{AlOAI}=\mathrm{AlO}+\mathrm{Al}$ & $1.0 \mathrm{E} 15$ & 0. & 133199.94 \\
11 & $\mathrm{Al}=\mathrm{Al}(\mathrm{I})$ & $1.0 \mathrm{E} 14$ & 0. & 0. \\
12 & $\mathrm{Al}_{2} \mathrm{O}_{3}=\mathrm{Al} \mathrm{O}_{3}(\mathrm{I})$ & $1.0 \mathrm{E} 14$ & 0. & 0. \\
\hline
\end{tabular}

\section{Particles Size Effect}

Particle size is one of the important parameters in the generation and combustion of aluminum, various researchers examine using various sizes ranging from nanometers to $\mu \mathrm{m}[12,22]$. As part of this research, as much data as possible is collected, documented, and collected in the general format in Table 1. Only sources are used where variations in the data are sufficient to show trends. Many other sources where data were obtained in a set of test conditions are not included. A database of about 400 datum points was compiled 
and analyzed to evaluate the effects of various parameters on the burning time of aluminum. The results of the study are presented below.

Table 1. Available Aluminum combustion data [23]

\begin{tabular}{|c|c|c|c|c|c|c|c|c|}
\hline \multirow{2}{*}{$D_{0}, \mu \mathrm{m}$} & \multirow{2}{*}{$\mathrm{T}_{0}, \mathrm{~K}$} & \multirow[b]{2}{*}{ p, atm } & \multicolumn{5}{|c|}{ Gas Concentration \% } & \multirow{2}{*}{ reff } \\
\hline & & & $\mathrm{H}_{2} \mathrm{O}$ & $\mathrm{O}_{2}$ & $\mathrm{CO}_{2}$ & CO & $\mathbf{N}_{2}$ & \\
\hline $10-42$ & 150 & $9-20$ & 0 & $20-50$ & $20-50$ & 0 & 0 & [6] \\
\hline $60-96$ & $2200-3200$ & $1-204$ & $0.5-50$ & $0-27$ & $9-50$ & $9-41$ & $9-41$ & [24] \\
\hline $300-760$ & 1809-1827 & 1 & $29-31$ & $10-25$ & $27-30$ & $15-49$ & $46-64$ & {$[25,26]$} \\
\hline 20 & 2225-2775 & $85-34$ & 0 & 99 & 0 & 0 & 1 & [27] \\
\hline $35-40$ & 298 & $1-39$ & 0 & 21 & 0 & 0 & 79 & {$[28,29]$} \\
\hline $40-70$ & 3000 & 1 & $66-89$ & $11-16$ & $0-18$ & 0 & 0 & [30] \\
\hline $40-170$ & 300 & 1 & 31.1 & 10.7 & 15.6 & 0 & 42.6 & [31] \\
\hline
\end{tabular}

This brief summary is not necessarily comprehensive but is intended to identify the main research contributions, especially where aluminum burning time data is available which can be correlated with other researchers. A brief description of their technique is included along with a discussion of their results and conclusions. For simplicity, research has been separated by techniques used to ignite aluminum particles: propellant, gas burners, lasers, ash, and shock.

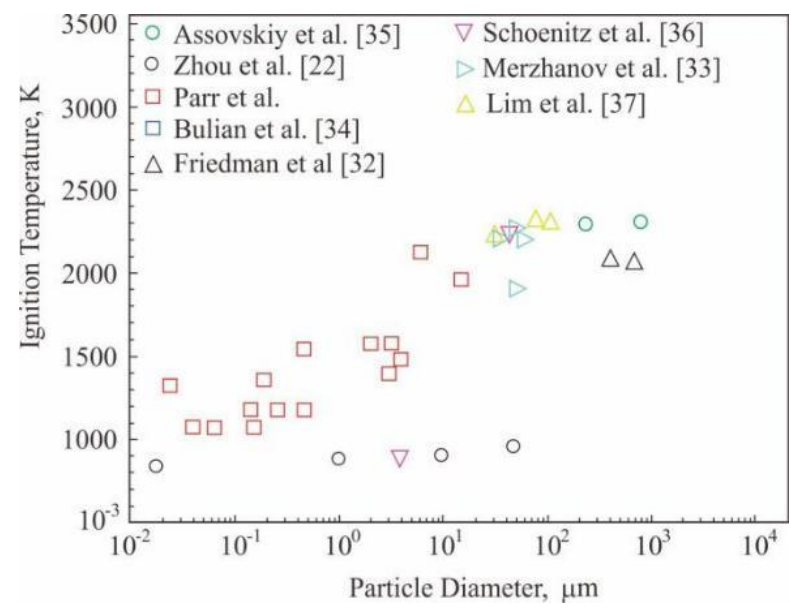

Figure 3. Ignition temperature of aluminum particle as a function of particle diameter.

The particle ignition temperature and combustion rate must be determined as input parameters in this analysis. Picture. 2 shows the ignition temperature of aluminum particles observed experimentally as a function of particle size in an oxygen-containing environment [22, 32-37]. For particles with diameters greater than $100 \mu \mathrm{m}$, most experimental studies have shown that ignition takes place at temperatures near the melting point of aluminum oxide (eg, $2350 \mathrm{~K}$ ). Because each aluminum particle is covered by a resistant oxide shell, he argues that the particle does not ignite until the oxide shell melts or breaks near its melting temperature under the influence of aluminum thermal expansion. For particles with diameters of $1-100 \mu \mathrm{m}$, however, ignition can be achieved over a wide temperature range from 1300 to $2300 \mathrm{~K}$. For nano-sized particles, ignition has been reported to occur at temperatures as low as $900 \mathrm{~K}[34,38]$. The low ignition temperature can be attributed to aluminum oxidation and polymorphic phase transformation of the alumina shell $[18,39]$, or cap of the oxide layer due to thermal expansion [40]. In this study, the results of the experimental data curve, as shown by the dotted line in Fig. 2, used for particle ignition temperature. 


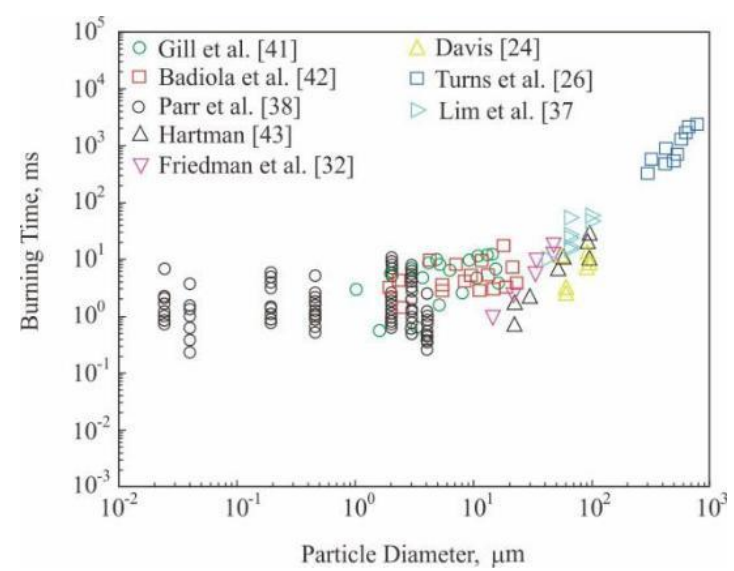

Figure 4. Comparison of measured burning times of aluminum as a function of particle diameter

The mechanism of combustion of nanoaluminum particles can be determined by comparing the measured and calculated combustion time. The combustion time dependence on particle size, pressure, and temperature can be used to gain insight into the mechanism of combustion. Figure 4 shows a comparison of the measured combustion time with theoretical counterparts under diffusion controlled conditions. Experimental data on the measured combustion time of aluminum particles are available in reference.[24, 26, 32, 37, 38, 41-43].

For nanoaluminum particles, the calculated gas phase diffusion time is some order of magnitude lower than the combustion time measured for nano-aluminum particles. As a result, mass diffusion through a gas phase mixture does not control the rate of combustion of nanoaluminum particles. Because the chemical rate constants and the mass diffusion coefficient in the oxide layer are less well known parameters, a comparison of the time scale of the characteristics of mass diffusion and chemical kinetics is not possible. Particle size gives a weak effect on the combustion of nano-aluminum particles. The burning time has a size dependence of the form $\mathrm{Tb}=\mathrm{aDpn}$, where the exponent $\mathrm{n}$ is $\sim 0.3$ [44]. The diameter exponents are lower than the unit due to cracks in the oxide layer and / or sintering and agglomeration of particles [45]. Cracks in the oxide layer increase the fractal dimension of the particle surface, while the particle volume is negatively affected. The resulting diameter exponents are significantly lower than the unit in kinetic controlled conditions. In addition, particles tend to aggregate during combustion and the resulting combustion time may not match the initial particle size. Furthermore, gas pressure and temperature have a strong effect on the combustion time of nanoaluminum particles.

The combustion time is an exponential function of temperature, with activation energy in the range of 50-144 $\mathrm{kJ} / \mathrm{mol}$ [44]. This decreases by a factor of four when the pressure increases from 8 to $32 \mathrm{~atm}$ [46]. Note that, in the free molecular regime, the diffusion time scale of the gas phase is proportional to the square root of temperature, whereas the time scale of diffusion of mass through the oxide layer and chemical kinetics is an exponential function of temperature. This, together with the observed time dependence of the observed size, not only proves the fact that mass diffusion through a gas phase mixture is not a rate control process, but also shows the rate of combustion of aluminum nanoparticles controlled by chemical kinetics. Note that chemical rate constants are less well known parameters and need further investigation. In addition, several important phenomena such as sintering and agglomeration of particles and cracking of the oxide layer must be considered before a comparison can be drawn between predictions and experimental data. This phenomenon can be considered in future work to develop a rigorous aluminum nanoparticle combustion model [10]. 


\section{OXYgen Content EfFEct}

Measurement of wavelength dispersive spectroscopy in the study of Dreizin (1999) showed the presence of oxygen in the interior of the particle, confirming our previous measurements made for particles burning in the air. Oxygen is not distributed uniformly in particles. Instead, areas with high oxygen content (up to $11 \%$ atoms) are mixed with areas of pure aluminum. Backscattering electron (BSE) images were collected for several cross sections of particles to visualize phases with different oxygen contents. The strength of the BSE signal is proportional to the average number of atoms of the material and provides good contrast for the oxygen-rich (dark) and oxygen (bright) zones as shown in Fig. 5 [47].

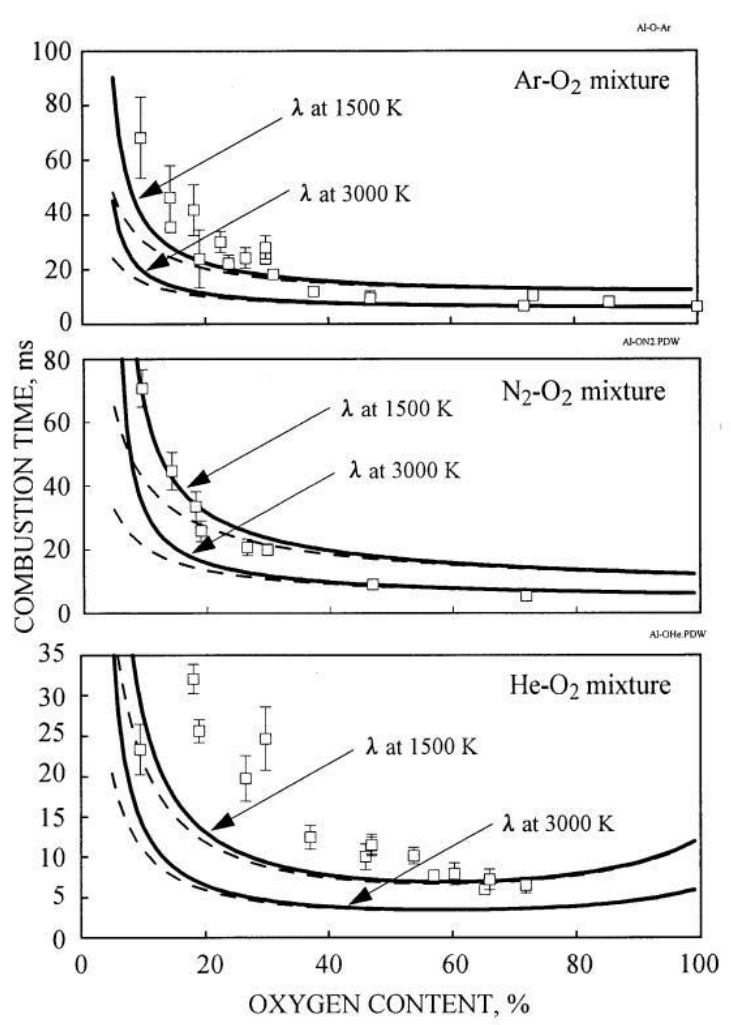

(a)

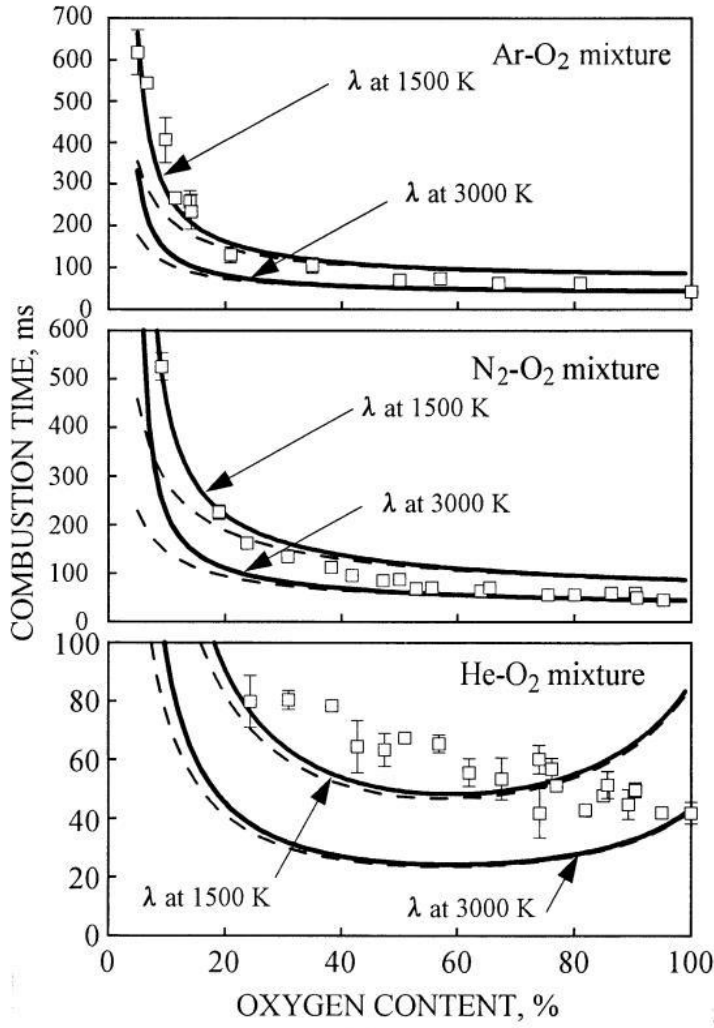

(b)

Figure 5. The experimental and estimated from the " $\mathrm{d}^{2}$ law" times of combustion for $90 \mathrm{~mm}$ (a) and $250 \mathrm{~mm}$ (b) diameter aluminum particles in different gas mixtures [47].

The measured combustion time is plotted against the oxygen content for each diluting mixture in FIG. 6. Each data point is an average of six or more measurements. In comparison, curves showing combustion time, $t$, calculated using "d2-law" for burning droplets are also plotted. Details and comparisons of experimental and computational combustion times are discussed below.

\section{SUMmARY}

Particle size is very influential in various conditions in the combustion of aluminum in this case, namely aluminum particle size and oxygen content used in combustion, the smaller the aluminum particle size, the ignition temperature will be lower while the burning time will be faster as the particle size decreases. Oxygen content also greatly influences the process of combustion of aluminum where the richer the oxygen, the faster burning time and higher temperatures

\section{REFERENCES}

1. J. K. Sambamurthi, E. W. Price, and R. K. Sigmant, "Aluminum Agglomeration in SolidPropellant Combustion," AIAA Journal, vol. 22, pp. 1132-1138, 1984.

2. A. S. Sharipov and A. M. Starik, "Theoretical Study of the Reactions of Ethanol with Aluminum and Aluminum Oxide," The Journal of Physical Chemistry A, vol. 119, pp. 3897-3904, 2015/04/30 2015. 
3. A. M. Starik, P. S. Kuleshov, A. S. Sharipov, and N. S. Titova, "Kinetics of Ignition and Combustion in the Al-CH4-O2 System," Energy \& Fuels, vol. 28, pp. 6579-6588, 2014/10/16 2014.

4. B. Evans, N. Favorito, and K. Kuo, "Oxidizer-Type and Aluminum-Particle Addition Effects on Solid-Fuel Burning Behavior," in 42nd AIAA/ASME/SAE/ASEE Joint Propulsion Conference \& Exhibit, ed: American Institute of Aeronautics and Astronautics, 2006.

5. V. Yang, T. Brill, and W. Ren, "Solid Propellant Chemistry, Combustion, and Motor Interior Ballistics, Prog," Astronaut. Aeronaut, vol. 185, pp. 663-688, 2000.

6. T. Bazyn, H. Krier, and N. Glumac, "Evidence for the transition from the diffusion-limit in aluminum particle combustion," Proceedings of the Combustion Institute, vol. 31, pp. 2021-2028, 2007/01/01/2007.

7. V. B. Storozhev and A. N. Yermakov, "Activation of aluminum nanopowder combustion in water vapor by $\mathrm{O} 2$ additions," Combustion and Flame, vol. 200, pp. 82-84, 2019/02/01/2019.

8. L. Ya. Kashporov, Y. E. Sheludyak, and V. V. Ukhov, "Combustion of aluminum-based mixtures," Combustion Explosion and Shock Waves - COMBUST EXPL SHOCK WAVES-ENGL, vol. 30, pp. 792-795, 11/01 1994.

9. G. A. Risha, S. F. Son, R. A. Yetter, V. Yang, and B. C. Tappan, "Combustion of nanoaluminum and liquid water," Proceedings of the Combustion Institute, vol. 31, pp. 2029-2036, 2007/01/01/2007.

10. D. S. Sundaram, P. Puri, and V. Yang, "A general theory of ignition and combustion of nano- and micron-sized aluminum particles," Combustion and Flame, vol. 169, pp. 94-109, 2016/07/01/2016.

11. S. Alavi, J. W. Mintmire, and D. L. Thompson, "Molecular Dynamics Simulations of the Oxidation of Aluminum Nanoparticles," The Journal of Physical Chemistry B, vol. 109, pp. 209-214, 2005/01/01 2005.

12. P. Puri and V. Yang, "Effect of Particle Size on Melting of Aluminum at Nano Scales," The Journal of Physical Chemistry C, vol. 111, pp. 11776-11783, 2007/08/01 2007.

13. Y. Huang, G. A. Risha, V. Yang, and R. A. Yetter, "Effect of particle size on combustion of aluminum particle dust in air," Combustion and Flame, vol. 156, pp. 5-13, 2009/01/01/ 2009.

14. T. Bazyn, H. Krier, and N. Glumac, "Oxidizer and Pressure Effects on the Combustion of 10-micron Aluminum Particles," Journal of Propulsion and Power, vol. 21, pp. 577582, 2005/07/01 2005.

15. S. W. Chung, E. A. Guliants, C. E. Bunker, P. A. Jelliss, and S. W. Buckner, "Sizedependent nanoparticle reaction enthalpy: Oxidation of aluminum nanoparticles," Journal of Physics and Chemistry of Solids, vol. 72, pp. 719-724, 2011/06/01/2011.

16. K. P. Brooks and M. W. Beckstead, "Dynamics of aluminum combustion," Journal of Propulsion and Power, vol. 11, pp. 769-780, 1995/07/01 1995.

17. Q. Li, G. Zhang, Y. Zheng, J. Liu, and X. Li, "Investigation on the correlations between thermal behaviors and explosion severity of aluminum dust/air mixtures," Powder Technology, vol. 355, pp. 582-592, 2019/10/01/ 2019.

18. M. A. Trunov, M. Schoenitz, X. Zhu, and E. L. Dreizin, "Effect of polymorphic phase transformations in $\mathrm{Al} 2 \mathrm{O} 3$ film on oxidation kinetics of aluminum powders," Combustion and Flame, vol. 140, pp. 310-318, 2005/03/01/ 2005.

19. Y.-T. Zheng, M. He, G.-X. Cheng, Z. Zhang, F.-Z. Xuan, and Z. Wang, "Effect of ionization on the oxidation kinetics of aluminum nanoparticles," Chemical Physics Letters, vol. 696, pp. 8-11, 2018/03/16/ 2018.

20. M.-V. Coulet, B. Rufino, P.-H. Esposito, T. Neisius, O. Isnard, and R. Denoyel, "Oxidation Mechanism of Aluminum Nanopowders," The Journal of Physical Chemistry C, vol. 119, pp. 25063-25070, 2015/11/05 2015.

21. Y. Feng, Z. Xia, L. Huang, and X. Yan, "Experimental investigation on the combustion characteristics of aluminum in air," Acta Astronautica, vol. 129, pp. 1-7, 2016/12/01/ 2016.

22. Y. n. Zhou, J. Liu, D. Liang, W. Shi, W. Yang, and J. Zhou, "Effect of particle size and oxygen content on ignition and combustion of aluminum particles," Chinese Journal of Aeronautics, vol. 30, pp. 1835-1843, 2017/12/01/ 2017.

23. M. Beckstead, "Correlating Aluminum Burning Times," Combust., Expl., Shock Waves, vol. 41, pp. 533-546, 09/01 2005.

24. A. Davis, "Solid propellants: The combustion of particles of metal ingredients," Combustion and Flame, vol. 7, 359-367, 1963/01/01/1963.

25. S. Wong and S. Turns, "Ignition of aluminum slurry droplets," Combustion Science and Technology, vol. 52, 221-242, 1987. 
26. S. R. Turns, S. C. Wong, and E. Ryba, "Combustion of Aluminum-Based Slurry Agglomerates," Combustion Science and Technology, vol. 54, pp. 299-318, 1987/08/01 1987.

27. T. A. Roberts, R. L. Burton, and H. Krier, "Ignition and combustion of aluminummagnesium alloy particles in $\mathrm{O} 2$ at high pressures," Combustion and Flame, vol. 92, pp. 125-143, 1993/01/01/ 1993.

28. M. Marion, C. Chauveau, and I. GöKalp, "Studies on the Ignition and Burning of Levitated Aluminum Particles," Combustion Science and Technology, vol. 115, pp. 369-390, 1996/06/01 1996.

29. M. Marion, C. Chauveau, and I. Gokalp, "Studies on the ignition and burning of levitated aluminum particles," in 31st Joint Propulsion Conference and Exhibit, ed: American Institute of Aeronautics and Astronautics, 1995.

30. S. E. Olsen and M. W. Beckstead, "Burn time measurements of single aluminum particles in steam and CO2 mixtures," Journal of Propulsion and Power, vol. 12, pp. 662-671, 1996/07/01 1996.

31. Y. Feng, Z. Xia, L. Huang, and L. Ma, "Effect of ambient temperature on the ignition and combustion process of single aluminium particles," Energy, vol. 162, pp. 618-629, 2018/11/01/2018.

32. R. Friedman and A. Maček, "Ignition and combustion of aluminium particles in hot ambient gases," Combustion and Flame, vol. 6, pp. 9-19, 1962/01/01/ 1962.

33. A. G. Merzhanov, Y. M. Grigorjev, and Y. A. Gal'chenko, "Aluminium ignition," Combustion and Flame, vol. 29, pp. 1-14, 1977/01/01/ 1977.

34. C. Bulian, T. Kerr, and J. Puszynski, "Ignition studies of aluminum and metal oxide nanopowders," in 31st Proc. Int. Pyrotech. Seminar, 2004, pp. 327-338.

35. I. Assovskiy, O. Zhigalina, and V. Kolesnikov-Svinarev, "Gravity effect in aluminum droplet ignition and combustion," in 5th International Microgravity Combustion Workshop, Cleveland, $\mathrm{OH}, 1999, \mathrm{pp} .18-20$.

36. M. Schoenitz, C.-M. Chen, and E. L. Dreizin, "Oxidation of Aluminum Particles in the Presence of Water," The Journal of Physical Chemistry B, vol. 113, pp. 5136-5140, 2009/04/16 2009.

37. J. Lim, "Burning and Ignition Characteristics of Single Aluminum and Magnesium Particle," in AIAA Guidance, Navigation, and Control Conference, ed: American Institute of Aeronautics and Astronautics, 2010.

38. T. Parr, C. Johnson, D. Hanson-Parr, K. Higa, and K. Wilson, "Evaluation of advanced fuels for underwater propulsion," in 39th JANNAF Combustion Subcommittee Meeting, 2003.

39. M. A. Trunov, M. Schoenitz, and E. L. Dreizin, "Ignition of Aluminum Powders Under Different Experimental Conditions," Propellants, Explosives, Pyrotechnics, vol. 30, pp. 36-43, 2005/02/01 2005.

40. A. Rai, D. Lee, K. Park, and M. R. Zachariah, "Importance of Phase Change of Aluminum in Oxidation of Aluminum Nanoparticles," The Journal of Physical Chemistry B, vol. 108, pp. 14793-14795, 2004/09/01 2004.

41. R. J. Gill, C. Badiola, and E. L. Dreizin, "Combustion times and emission profiles of micron-sized aluminum particles burning in different environments," Combustion and Flame, vol. 157, pp. 2015-2023, 2010/11/01/2010.

42. C. Badiola, R. J. Gill, and E. L. Dreizin, "Combustion characteristics of micron-sized aluminum particles in oxygenated environments," Combustion and Flame, vol. 158, pp. 2064-2070, 2011/10/01/2011.

43. K. Hartman, "Ignition and combustion of aluminum particles in propellant flame gases," 8th JANNAF Combustion Mtg, vol. 1, pp. 1-24, 1971.

44. D. Sundaram, V. Yang, and V. Zarko, "Combustion of Nano Aluminum Particles (Review)," Combustion Explosion and Shock Waves, vol. 51, pp. 173-196, 05/12 2015.

45. P. Chakraborty and M. R. Zachariah, "Do nanoenergetic particles remain nano-sized during combustion?," Combustion and Flame, vol. 161, pp. 1408-1416, 2014/05/01/ 2014.

46. T. Bazyn, H. Krier, and N. Glumac, "Combustion of nanoaluminum at elevated pressure and temperature behind reflected shock waves," Combustion and Flame, vol. 145, pp. 703-713, 2006/06/01/ 2006.

47. E. L. Dreizin, "On the mechanism of asymmetric aluminum particle combustion," Combustion and Flame, vol. 117, pp. 841-850, 1999/06/01/ 1999. 